www.jmscr.igmpublication.org

Impact Factor 3.79

Index Copernicus Value: 5.88 ISSN (e)-2347-176x ISSN (p) 2455-0450 crossref DOI: http://dx.doi.org/10.18535/jmscr/v3i11.17

\author{
Journal Of Medical Science And Clinical Research \\ IGM Publication \\ An Official Publication of IGM Publication
}

\title{
Prevalence of Various Complications in Type II Diabetes Mellitus in Rural Medical College of Central India - A study
}

\author{
Authors \\ Dr. Jyoti Tiwari ${ }^{1}$, Dr. Jagrati Kiran Naagar ${ }^{2}$, Dr. (Prof). K.K. Kawre ${ }^{3}$ \\ ${ }^{1}$ Assistant Professor Deptt.of Medicine, Bundelkhand Medical College, Sagar, MP 470001. \\ ${ }^{2}$ Assistant Professor Deptt.of Obs / Gyn, Bundelkhand Medical College, Sagar MP. \\ ${ }^{3}$ Professor, Deptt. of Medicine, Mahatma Gandhi Medical College, Bhopal, MP. \\ Corresponding Author \\ Dr . Jyoti Tiwari \\ Sagar Diagnostic Centre, Near City Kotwali, Chakraghat Sagar, MP 470002
}

Email:drtiwari@rediffmail.com,drtiwari2011@gmail.com Phone number 09827760212

\begin{abstract}
-
Aim of study- To detect prevalence of various complications of type 2 diabetes mellitus in a rural tertiary government health care hospital of central india.

Materials and methods -Diabetes mellitus is now an increasing health concern for both urban as well as rural populations of India. In this study we evaluated the prevalence of various microvascular and macro vascular complications in patients of OPD/IPD of Bundelkhand Medical College, Sagar MP. The study conducted from Apr 2014- Sept 2014.Total 1970 patients were included in the study by random sampling. Detailed history, clinical examinations, anthropometric measurements and biochemical examinations were done. American Diabetes Association criteria (ADA) were used for diagnosis of diabetes mellitus and standard definitions were used to define the diabetic patients. Data were analysed by SPSS software version 12.

Results- Among the 1970 patients studied 1025 (52\%), patients were male \& 945(48\%), patients were female. Out of which 270 patients were diabetic (13.7\%). The associated diabetic comlications was as followsNeuropathy $(n=70,25.9 \%)$, Nephropathy $(n=43,15,5 \%)$, Coronary artery disease CAD $(n=42 \%, 15.5)$, Retinopathy $(n=22,8.1 \%)$, Peripheral vascular disease $(n=15,5.5 \%)$, Cerebrovascular accidents $(n=10,3.7 \%)$. Along with the complications we have also observed a rising trend in the diabetic complications associated with increased duration of illness as well as persistently high blood sugar levels.

Conclusions- As the complications of diabetes are higher with higher blood sugars levels and long duration of diabetes hence the disease needs to be diagnosed and treated as early as possible by doing routine screening for diabetes \& diabetes awareness programme should be there for early diagnosis of the disease and treatment to prevent complications.
\end{abstract}

Key words - Diabetes mellitus, complications, blood sugar, rural.CAD

\section{INTRODUCTION}

Type 2 diabetes is a common condition with high morbidity and mortality rates. Its diagnosis appears to be increasing ${ }^{[1-3]}$, probably reflecting an underlying rise in prevalence of disease..$^{[1,2]}$
Type 2 diabetes mellitus consists of an array of dysfunctions characterized by hyperglycemia resulting from the combination of increased resistance to insulin action, inadequate insulin secretion by beta cells of pancreas, and excessive 
or inappropriate glucagon secretions. The American diabetes association (ADA) has condensed recommendations for standards of medical care in diabetes mellitus. ${ }^{3}$ This is as follows -

- Prediabetes

- Self-management education

- Nutrition

- Physical activity

- Smoking cessation

- Psychosocial care

- Immunizations

- Glycemic treatment

- Therapeutic targets

- Diagnosis and treatment of vascular complications

- Intensification of insulin therapy in type 2 diabetes

Diagnostic criteria by the American Diabetes Association (ADA) include the following. ${ }^{[4]}$

- A fasting plasma glucose (FPG) level of $126 \mathrm{mg} / \mathrm{dL}$ (7.0 mmol/L) or higher, on two seperate occasions or

- A 2-hour plasma glucose level of 200 $\mathrm{mg} / \mathrm{dL}(11.1 \mathrm{mmol} / \mathrm{L})$ or higher during a 75-g oral glucose tolerance test (OGTT), or

- A random plasma glucose of $200 \mathrm{mg} / \mathrm{dL}$ $(11.1 \mathrm{mmol} / \mathrm{L})$ or higher in a patient with classic symptoms of hyperglycemia or hyperglycemic crisis.

Diabetes is a group of chronic diseases characterized by hyperglycemia. Generally, the injurious effects of hyperglycemia are separated into macrovascular complications (coronary artery disease, peripheral arterial disease, and stroke) and microvascular complications (diabetic nephropathy, neuropathy, and retinopathy).

Diabetic retinopathy may be the most common microvascular complication of diabetes. It is responsible for $\sim 10,000$ new cases of blindness every year in the United States alone.
Diabetic nephropathy is the leading cause of renal failure in the United States. It is defined by proteinuria $>500 \mathrm{mg}$ in 24 hours in the setting of diabetes.

Diabetic neuropathy is recognized by the American Diabetes Association (ADA) as "the presence of symptoms and / or signs of peripheral nerve dysfunctions in people with diabetes after the exclusion of other causes."

The central pathological mechanisms in macrovascular disease is the process of atherosclerosis, which leads to narrowing of arterial walls throughout the body. Diabetes increases the risk that an individual will develop cardiovascular disease (CVD).

Diabetes is also a strong independent predictor of increased risk of stroke and cerebrovascular disease, as in coronary artery disease.

Approaches for prevention of diabetic complications include the following:

- HbA1c every 3-6 months

- Yearly dilated eye examinations

- Annual microalbumin checks

- Foot examinations at each visit

- Blood pressure < 130/80 mm Hg or lower in diabetic nephropathy

- Statin therapy to reduce low-density lipoprotein cholesterol

Diabetes mellitus is a major health problem worldwide. Approximately 190 million people around the world are suffering from diabetes now $\&$ and this data will rise to 330 million people with diabetes by 2025 and 360 million Diabetic people by $2030 .^{[5]}$ The incidence will be higher in developing countries. Eighty percent people live in low and middle income countries. In prediction, India along with China account for nearly a third of the estimated 300 million adult diabetics by the year $2025{ }^{[6]}$ Recent surveys indicate that diabetes now affects $10-16 \%$ of urban population and $5-8 \%$ of rural populations in India, while the actual epidemic is believed to be emerging in the rural areas. $^{[7,8]}$ Indians are susceptible to premature onset of Diabetes mellitus which in turn leads to rapid progression of chronic vascular 
complications, incurring heavy burden on health care systems in India, where the health care facilities are already less specially in the rural areas of the country.

\section{MATERIAL AND METHODS}

The study was conducted in the OPD and IPD of department of Medicine in Bundelkhand Medical College Sagar MP, a rural area of central india. The duration of study was 6 months starting from April 2014 to Sept 2014. All the patients attending the OPD and those admitted in medicine wards were registered for the study aging 20 to 75 years of age.

The inclusion criteria was -All patients coming to OPD and those who were admitted in medicine wards were included in the study during the specified period. Guidelines for detection of diabetes were followed which are laid by American society of Diabetology (ADA). Blood examination was done on two separate occasions before the diagnosis of diabetes was made. Written informed consent was taken from all the patients.

\section{Inclusion criteria-}

All patients aging 20-75 yrs of age attending Medicine OPD and admitted in wards.

Fasting plasma glucose $>126 \mathrm{mg} / \mathrm{dl}$ on two separate occasions after 8-10 hrs fasting.

In a patient with classical symptoms of diabetes Random blood glucose of $>200$ mg/dl.

\section{Exclusion criteria-}

Any other serious illness

Those who have refused for study

Pregnancy

Age below 20 or more than 75 years

Diabtes was diagnosed by american diabetes association (ADA) criteria. FBS more than 126 $\mathrm{mg} / \mathrm{dl}$ on two separate occasions or according to the confirmed diagnosis of diabetes as per the clinical records of the patient and previous treatment history. A detailed clinical history with present, past, personal and treatment history was obtained. A detailed clinical examination including general examinations, systemic examinations, Blood pressure, anthropometric examinations, BMI, Dilated Fundus examinations was done. Then $5 \mathrm{ml}$ venous blood was withdrawn with overnight fasting of 8-10 hrs and then fasting blood glucose examinatios, serum lipid profile, serum creatinine, blood urea and $\mathrm{CBC}$ was done. Urine is sent for routine urine exanminations and microalbumin. Routine ECG and X-Ray chest was done of every patient.

Minnesota criteria was used for diagnosis of CAD. If there is any abnormal findings on ECG, Or if there is positive history of effort angina and paroxysmal nocturnal dyspnoea. For diagnosing peripheral arterial disease all the peripheral pulsations were noted in every patient, and history of intermittent claudications was taken. Any visible amputations were seen. Other causes of claudications are excluded like burgers disease. For diagnosis of nuropathy on clinical history and on examinations bilateral distal sensory loss, any major sensory loss, absent ankle jerks are taken into considerations. Retinopathy was diagnosed by detailed dilated fundoscopy examinations. For Nephropathy any history of oligurea or anurea, feet swelling and presence of albumin or microalbumin in urine was seen. For CVA any positive history of stroke, and history of hemiplegia, aphasia, dysarthria, sudden loss of conciousness, or residual weakness on examinations, or a positive CT SCAN / MRI scan was taken into account.

Then a master chart was prepared with all the available data in hand, and then this data was analysed using SPSS software version 12 and various results were obtained.

\section{RESULTS}

After obtaining the data a master chart was prepared and stastitistical analysis was performed by using SPSS software.

In our duration of study total 1970 cases were registered in our study. Out of which 1025 (52\%) 


\section{JMSCR Vol||3||Issue ||11||Page 8214-8219||November}

cases were males, and $945(48 \%)$ cases were females.

Out of these 1970 patients 270 cases were of diabetes mellitus. Out of 270 , newly detected cases were $105(39.8 \%)$ and rest of the cases 162 $(60 \%)$ were of previously detected diabetes mellitus type 2, which was already diagnosed and was on regular or irregular treatments, and only 3 cases $(0.2 \%)$ of type 1 diabetes was there in this sample size.

Mean age of diabetes mellitus was $54 \pm 13.3$ years, so the maximum incidence of diabetes was seen in 42 to 58 years of age. The patients presenting with various diabetic complications, as CAD $(n=42)$, cerebrovascular accidents $(n=10), \operatorname{PVD}(n=15)$,
Retinopathy $(\mathrm{n}=22)$, neuropathy $(\mathrm{n}=70)$ and nephropathy $(n=43)$ was seen in the diabetic patients .Classical symptoms of diabetes as polydipsia, polyphagia and increased hunger was seen $(n=55)$ without diabetic complications. The higher the BMI there are more chances of diabetic complications as CAD and cerebrovascular accidents. As Table-1 depicts it very nicely that as BMI 29 and 30 is associated with higher risk of CAD and cerebrovascular accidents. Higher the FBS and PPBS in diabetic patients higher the chances of complications. Same is for higher cholestrol values which is also associated with higher rate of complications like CAD.

\section{TABLE-1 VARIOUS METABOLIC PARAMETERS OF DIABETES MALLITUS -}

\begin{tabular}{|l|c|c|c|c|c|c|c|}
\hline $\begin{array}{l}\text { Metabolic } \\
\text { Parameters } \\
\text { in DM }\end{array}$ & $\begin{array}{l}\text { Diabetes } \\
\text { mellitus } \\
(\mathrm{n}=270)\end{array}$ & $\begin{array}{c}\text { CAD } \\
(\mathrm{n}=42)\end{array}$ & $\begin{array}{c}\text { Diabetic } \\
\text { Neuropathy } \\
(\mathrm{n}=70)\end{array}$ & $\begin{array}{c}\text { Diabetic } \\
\text { Retinopathy } \\
(\mathrm{n}=22)\end{array}$ & $\begin{array}{c}\text { CVA } \\
(\mathrm{n}=10)\end{array}$ & $\begin{array}{c}\text { Diabetic } \\
\text { Nephropathy } \\
(\mathrm{n}=43)\end{array}$ & $\begin{array}{c}\text { PVD } \\
(\mathrm{n}=15)\end{array}$ \\
\hline Age & $54 \pm 13.3$ & 52 & 67 & 56 & 66 & 55 & 55 \\
\hline Weight & $76 \pm 7.8$ & 82 & 74 & 70 & 83.3 & 78 & 75.5 \\
\hline Height & $159 \pm 12.8$ & 160 & 164 & 166 & 164 & 170 & 172 \\
\hline BMI & $28 \pm 12.8$ & 29 & 26.6 & 22 & 30 & 26 & 28 \\
\hline FBS mg/dl & $210 \pm 78.8$ & 280 & 270 & 260 & 288 & 280 & 260 \\
\hline PPBSmg/dl & $310 \pm 95$ & 380 & 345 & 310 & 370 & 400 & 355 \\
\hline Creatinine & $1.1 \pm 0.4$ & 1.12 & 1.11 & 1.0 & 1.3 & 1.5 & 1.22 \\
\hline Cholestrol & $200 \pm 45.5$ & 245 & 200 & 210 & 245 & 210 & 230 \\
\hline
\end{tabular}

In Table - 2 we compared the prevalence of various complications in diabetic patients with the non diabetic patients of the study group. The prevalence of various microvascular and macrovascular complications are higher in diabetic group .

\section{TABLE -2 VARIOUS COMPLICATIONS IN DIABETIC AND NON DIABETIC PATIENTS} IN STUDY GROUP -

\begin{tabular}{|l|c|c|}
\hline Complications & $\begin{array}{c}\text { Diabetes mallitus } \\
(\mathrm{n}=270)\end{array}$ & $\begin{array}{c}\text { Non diabetic patients } \\
(\mathrm{n}=1700)\end{array}$ \\
\hline Coronary artery disease & $42(15.5 \%)$ & $33(1.94 \%)$ \\
\hline Cerebrovascular accidents & $10(3.7 \%)$ & $3(0.1 \%)$ \\
\hline Peripheral vascular disease & $15(5.5 \%)$ & $11(0.6 \%)$ \\
\hline Retinopathy & $22(8.1 \%)$ & $5(2.8 \%)$ \\
\hline Neuropathy & $70(25.9 \%)$ & $52(3.0 \%)$ \\
\hline Nephropathy & $43(15.5 \%)$ & $32(1.8 \%)$ \\
\hline Polydipsia,polyphagia,hunger+ & $55(20.3 \%)$ & $56(3.2 \%)$ \\
\hline Cataract & $13(4.8 \%)$ & $26(1.5 \%)$ \\
\hline Total number of cases & $270(13.7 \%)$ & $1700(86.2 \%)$ \\
\hline
\end{tabular}


TABLE-3 DURATION OF DIABETES \& PREVALENCE OF DIABETIC COMLICATIONS

\begin{tabular}{|l|c|c|c|c|c|c|}
\hline $\begin{array}{l}\text { Duration of } \\
\text { diabetes in } \\
\text { years }\end{array}$ & $\begin{array}{c}\text { Diabetic } \\
\text { Neuropathy } \\
\text { cases\% }\end{array}$ & $\begin{array}{c}\text { CVA cases } \\
\%\end{array}$ & $\begin{array}{c}\text { CAD cases } \\
\%\end{array}$ & $\begin{array}{c}\text { Diabetic } \\
\text { Retinopathy } \\
\text { cases\% }\end{array}$ & $\begin{array}{c}\text { Diabetic } \\
\text { Nephropathy } \\
\text { Cases\% }\end{array}$ & $\begin{array}{c}\text { Peripheral } \\
\text { vascular } \\
\text { disease } \%\end{array}$ \\
\hline$<5 \mathrm{yrs}$ & $10(14 \%)$ & $3(30 \%)$ & $4(9.55 \%)$ & $2(9.2 \%)$ & $6(13.9 \%)$ & $2(13.3 \%)$ \\
\hline$>5 \mathrm{yrs}$ & $28(40 \%)$ & $6(60 \%)$ & $10(23.8 \%)$ & $8(36.3 \%)$ & $15(34.8 \%)$ & $5(33.3 \%)$ \\
\hline$>10 \mathrm{yrs}$ & $32(45.7 \%)$ & $1(10 \%)$ & $28(66.6 \%)$ & $12(54.5 \%)$ & $22(51.2 \%)$ & $8(53.3 \%)$ \\
\hline Total & $70(25.9 \%)$ & $10(3.7 \%)$ & $42(15.5 \%)$ & $22(8.1 \%)$ & $43(15.5 \%)$ & $15(5.5 \%)$ \\
\hline $\mathrm{P}$ value & $<0.0001$ & $<0.0001$ & $<0.0001$ & $<0.0001$ & $<0.0001$ & $<0.001$ \\
\hline
\end{tabular}

In Table -3 we have compared the prevalence of various complications in diabetic patients with respect to the duration of disease. We have devided it in three catagories less than $5 \mathrm{yrs}$, more than $5 \mathrm{yrs}$, and more than 10 yrs. We have observed maximum cases of CAD $(n=33) 66.6 \%$, afer the duration of more than 10 yrs, out of total cases of CAD $(n=42)$. The incidence of CVA was highest in the category of more than 5 yrs $(n=6)$ $60 \%$ cases out of total cases of CVA $(n=7)$. Similarly other complications also increses as the duration of disease is longer.

\section{DISCUSSIONS}

As we have conducted this study in our set up of rural medical college of central India, where the awareness regarding the diabetes is substantially low. Majority of the patients who were diagnosed in this study was already presented with symptomps and signs of diabetic complications at the time of diagnosis .Very few cases were presented with the minor symptoms or on routine examinations done before various surgical procedures. Total 55 cases presented with sypmtoms classical for diabetes melltus like polyurea and polydipsia and increased appetite and was not associated with diabetic complications at the time of diagnosis. These findings are similar to the study done by Drivsholm et $\mathrm{al}^{[9]}$ study. In our study we have found out CAD $(n=42) 15.5 \%$, Neuropathy ( =70) $25.9 \%$, Nephropathy $(n=43) 15.5 \%$. These findings are consistant with the study done by Weersurya et al ${ }^{[10]}$, they have found out CAD $26.9 \%$, Diabetic nephropathy $25.2 \%$, Neuropathy $29 \%$ in their study.In the study by Mohan et al ${ }^{[11]}$ results are not similar to our study. They have found out majority of cases of diabetic complication was Retinopathy $34.2 \%$, cases of CAD was low $7.9 \%$. In Hoorn study ${ }^{[12]}$ diabetic nephropathy was highest $48.3 \%$ and diabetic neuropathy was $26.7 \%$. These findings are also consistant with our study. The study done by Agrawal et al ${ }^{[13]}$ also shows the results similar to our study, in which Retinopathy was highest $32.5 \%$, Nephropathy $30.2 \%$, Neuropathy $26.8 \%$, CAD was found in $25.8 \%$. The study done by Nafisa et $\mathrm{al}^{[14]}$ which was done on the rural population of Goa also shows results similar to our study. They found Neuropathy 60\%, CAD $32.6 \%$, Retinopathy $15.4 \%$, Peripheral vascular disease $11.5 \%$, and Cerebrovascular accidents $6.9 \%$ in their study.

\section{CONCLUSIONS-}

As the prevalence of diabetes mallitus is rising and at the same time it is now affecting rural as well as urban people both .Similarly there are higher prevalence of complications at the time of initial diagnosis of the disease, because of unawareness of the disease. So it's a silent killer and treatment of various complications increases the burden of cost for the patients as well as for the govt. authorities of the country. There are higher prevalence of CAD $(n=42)$, Nephropathy $(\mathrm{n}=43)$, Retinopathy $(\mathrm{n}=22)$ and diabetic Neuropathy $(n=70)$ which is statistically very significant $(\mathrm{p}=<0.0001)$. Prevalence of Peripheral vascular disease $(n=15)$, and early cataract $(n=13)$, and CVA $(n=10)$ was also significant .So there should be mass screening campaigns of the patients for diabetes early detection and treatment 
before the onset of various complications to the patients .

\section{REFERENCES}

1. Gadsby R. Epidemiology of diabetes. Adv Drug Deliv Rev. 2002;54:1165-1172. doi: 10.1016/S0169-409X(02)00094-

7. [PubMed] [Cross Ref]

2. Newnham A, Ryan R, Khunti K, Majeed A. Prevalence of diagnosed diabetes mellitus in general practice in England and Wales, 1994 to 1998. Health Statistics Quarterly.2002;14:5-13.

3. American Diabetes Association. Standards of Medical Care in Diabetes-2015: Abridged for Primary Care Providers. Clinical Diabetes. 2015. 33(2):[Full Text].

4. Guideline] Diagnosis and classification of diabetes mellitus. Diabetes Care. 2010 Jan. 33 Suppl 1:S62-9.[Medline]. [Full Text].

5. Azizi F, Guoya MM, Vazirian P, Dolatshati P, Habbibian S. Screening for type 2 diabetes in the Iranian national programme:a preliminary report. East Mediterr Health J. 2003;9:1122-7. [PubMed]

6. Fall $\mathrm{CH}$. Non-industrialised countries and affluence. Br Med Bull. 2001;60:33-50. [PubMed]

7. Wild S, Roglic Green A, Sicree R, King H. Global prevalence of diabetes: estimates for the year 2000 and projections for 2030 . Diabetes Care. 2004;27:1047-53. [PubMed]

8. Pradeepa R, Mohan V. The changing scenario of the diabetes epidemic: implications for India. Indian J Med Res. 2002;116:121-32. [PubMed]

9. Drivsholm T, de Fine Olivarius N, Nielsen AB, Siersma V. Symptoms, signs and complications in newly diagnosed type 2 diabetic patients, and their relationship to glycaemia, blood pressure and weight. Diabetologia 2005;48(2):210-4.
10. Weerasuriya N, Siribaddana S, Dissanayake A, Subasinghe Z, Wariyapola D, Fernando DJ. Long-term complications in newly diagnosed Sri Lankan patients with type 2 diabetes mellitus. QJM 1998;91(6):439-43.

11. Premlatha G, Rema M, Mohan V. Complications of diabetes mellitus at diagnosis in South Indian type 2 diabetic patients. Int J Diab Dev Ctries 1998;18:14.

12. Spijkerman AM, Dekker JM, Nijpels G, Adriaanse MC,Kostense PJ, Ruwaard D, et al. Microvascular complications at time of diagnosis of type 2 diabetes are similar among diabetic patients detected by targeted screening and patients newly diagnosed in general practice: the Hoorn screening study. Diabetes Care 2003;26(9):2604-8.

13. Agrawal RP, OlaV, Bishnoi P,Gothwal S, Sirohi P,Agrawal R.Prevelence of micro \& macrovascular complications and their risk factors in type II diabetes mallitus. J Assoc Physicians India.2014 June;62(6):504-8.

14. Nafisa C Vaz, AM Ferreira,MS Kulkarni, Fredrick S Vaz,NR Pinto.Prevelence of Diabetic Complications in Rural Goa, India. Indian J Community Med.2011 OctDec;36(4):283-86. 